\title{
MIGRAÇÕES “RURAIS-URBANAS” PERMANENTEMENTE TEMPORÁRIAS NO CONTEXTO DO AGRONEGÓCIO PAULISTA
}

\author{
Lidiane Maciel $^{1}$ \\ Giovana Gonçalves Pereira ${ }^{2}$
}

\section{RESUMO}

O trabalho tem como objetivo realizar um debate sobre as condições de vida dos trabalhadores rurais migrantes que se deslocam, sobretudo do Nordeste brasileiro e Vale do Jequitinhonha mineiro para o interior de São Paulo - Região Central e de Ribeirão Preto - em busca de emprego e renda nas colheitas da laranja e corte de cana-de-açúcar. Pretende-se compor o mosaico de interações sociais através da análise de trajetórias migratórias qualitativas colhidas entre as cidades paulistas, principalmente Matão, no interior de São Paulo e Jaicós no Piauí. Essas trajetórias já demonstram inúmeras diferenciações entre os trabalhadores rurais da laranja e do corte de cana-de-açúcar. Como resultados preliminares verificamos que a migração altera as relações familiares, de gênero, geracionais e o modo de vida na "origem" e "destino" migratório. No caso das mulheres trabalhadoras rurais das colheitas da laranja e atividades complementares ao corte de cana-de-açúcar, no destino, a entrada no mercado de trabalho rural vinculado ao agronegócio às expõe a uma dupla jornada de trabalho impactando diretamente na produção de sua subjetividade e na origem impõe aos moradores o fim dos roçados. Nesse sentido, este trabalho lançará luz sobre essas questões.

Palavras-Chave: Migrações permanentemente temporárias; Agronegócio; Espaço de vida; Subjetividade.

\section{AS MIGRAÇÕES PERMANENTEMENTE TEMPORÁRIAS PARA O AGRONEGÓCIO PAULISTA $^{3}$}

\footnotetext{
${ }^{1}$ Professora - Substituta do Departamento de Educação, Ciências Sociais e Políticas públicas da Universidade Estadual Paulista - Júlio de Mesquita Filho, Campus Franca - Doutora em Sociologia pela Universidade Estadual de Campinas e pesquisadora participante do Projeto Temático: Observatórios das migrações em São Paulo (FAPESP/CNPq) sediado no Núcleo de Estudos de População "Elza Berquó" (NEPO/UNICAMP) e coordenado pela Profa. Dra. Rosana Baeninger. Email: lidianimaciel@gmail.com, ${ }^{2}$ Aluna do Programa de Pós-Graduação em Demografia - Nível Doutorado -, Mestra em Demografia, Bacharela e Licenciada em Ciências Sociais pela Universidade Estadual de Campinas (UNICAMP). Integrante do Projeto Temático "Observatório das Migrações em São Paulo" (FAPESP/CNPq) sediado no Núcleo de Estudos de População "Elza Berquó" (NEPO/UNICAMP) e coordenado pela Profa. Dra. Rosana Baeninger. Email: giovana.ggp@gmail.com

${ }^{3}$ Nota metodológica: O trabalho apresentado se realiza através do cruzamento das pesquisas realizadas pelas autoras desde 2009, o que compreende um trabalho de campo (Entrevistas semiestruturadas, biografias migratórias, e etnografias) realizado na Região Central e de Ribeirão Preto do Estado de São Paulo, abrangendo as cidades de São Carlos, Matão, Ribeirão Preto, Barrinha, Dobrada, Ibaté. E um trabalho de campo realizado nas cidades de Picos e Jaicós, no Alto médio Canindé, no Estado do Piauí. Tendo como objetivo um balanço comparativo o artigo se apropria de outros trabalhos empíricos, devidamente citados, realizados por diversos pesquisadores da área. A coleta de dados também foi amparada pela tabulação de dados quantitativos e qualitativos de diferentes bases, tais como Fundação SEADE; Relação Anual de Indicadores Sociais (RAIS), e CadÚnico. Por fim, os dados foram submetidos a diferentes tratamentos e análises qualitativas e quantitativos considerando o aporte teórico selecionado que descreveremos ao longo do artigo.
} 


\section{SEMINÁRIO DE PESQUISA EM CIÊNCIAS HUMANAS - SEPECH \\ Humanidades, Estado e desafios didático-científicos \\ Londrina, 27 a 29 de julho de 2016}

A Região Central do Estado de São Paulo, composta pelas Regiões de Governo de Araraquara e São Carlos, juntamente com a Região de Ribeirão Preto ${ }^{4}$, composta pelas Regiões de Governo de Ribeirão Preto e Jaboticabal, apresentaram nos últimos trinta anos uma dinâmica populacional e econômica vinculas ao mercado de trabalho rural estabelecido na região pós a década de 1970. O desenvolvimento do agronegócio atrelado à produção de etanol e suco concentrado de laranja destacaram nacionalmente e internacionalmente estas regiões, que passaram a ser vistas como polos de desenvolvimento social e econômico.

Beneficiadas pela expansão do complexo cafeeiro no século 19 (PACHECO, 1988; PIRES, 1995), pelo processo de modernização agrícola no século 20 (MÜLLER, 1985; ELIAS, 2003) e de mesmo modo pela internacionalização da economia brasileira (SILVA, 2003; CANO, 2011), as Regiões Administrativas Central e de Ribeirão Preto tornaram-se espaços privilegiados para o desenvolvimento de atividades agroindustriais, bem como, para a reorientação de pequenas e médias cidades na divisão internacional do trabalho (PEREIRA, 2015).

Sob essa conjuntura, os municípios de Sertãozinho e Matão, pertencentes, respectivamente as RG de Ribeirão Preto e de Araraquara, tiveram seus espaços urbanos, rurais e intra-urbanos reconfigurados pelos interesses de grandes holdings transformando-se em company towns (CÔRREA, 2006) e consequentemente em cidades do agronegócio (ELIAS, 2011 e 2013).

As cidades do agronegócio, de acordo com Elias e Pequeno (2006 e 2007), se traduzem pelo crescimento econômico e demográfico de pequenas e médias cidades, no território brasileiro, através da inserção de atividades agroindustriais e circundantes no parque industrial municipal. A produção industrial desses municípios visa o mercado internacional de commodities e vincula, desde o início, o plano local e regional ao global (ELIAS, 2013). O ponto-chave de inflexão desses municípios ocorreu na década de 1980 (Tabela 1), acompanhado pelo espraiamento do espaço intra-urbano e a constituição de novos bairros impulsionados pelo crescimento populacional ocasionado tanto pelo êxodo rural intra-regional e municipal, quanto pelas migrações de nordestinos e mineiros (PIRES, 1995; BAENINGER, 1998).

\begin{tabular}{|c|c|c|c|}
\hline Unidade Geográfica & $80-91$ & 91-00 & 00-10 \\
\hline Brasil & $1,93 \%$ & $1,63 \%$ & $1,17 \%$ \\
\hline São Paulo & $2,13 \%$ & $1,78 \%$ & $1,09 \%$ \\
\hline RG de Ribeirão & $2,86 \%$ & $1,91 \%$ & $1,64 \%$ \\
\hline Sertãozinho & $3,93 \%$ & $2,12 \%$ & $1,52 \%$ \\
\hline RG de Araraquara & $2,82 \%$ & $1,63 \%$ & $1,06 \%$ \\
\hline Matão & $4,77 \%$ & $1,42 \%$ & $0,69 \%$ \\
\hline
\end{tabular}

Tabela 1: Taxa Geométrica de Crescimento Populacional no país, no Estado de São Paulo, nas RG de Ribeirão Preto e de Araraquara e nos municípios de Matão e Sertãozinho (1980-2010)

Fonte: Censos Demográficos de 1980, 1991, 2000 e 2010. Informações dos Municípios Paulistas (Fundação SEADE).

\footnotetext{
${ }^{4}$ Classificação Fundação SEADE (Informações Municipais)
} 


\section{SEMINÁRIO DE PESQUISA EM CIÊNCIAS HUMANAS - SEPECH \\ Humanidades, Estado e desafios didático-científicos \\ Londrina, 27 a 29 de julho de 2016}

As populações de Sertãozinho e Matão passam, respectivamente, no período de 1980-1991, de 51.203 habitantes para 78.266 habitantes e de 37.822 habitantes para 63.154 habitantes (Tabela 2). Conquanto, a partir da década de 2000 observa-se uma diminuição das taxas de crescimento populacional dos municípios analisados (Tabela 1), o que ocasiona um incremento populacional, no período de 2000-2010, de 15.437 habitantes em Sertãozinho e de 5.074 habitantes em Matão. Todavia, esse cenário não simboliza que os movimentos migratórios direcionados a esses locais diminuíram, mas sim que tanto o estoque de migrantes do tipo rural-urbano diminuiu frente aos processos de urbanização e industrialização (PATARRA e RENNER, 1980; BAENINGER, 2012), quanto, ocorreu o aumento da circulação e convivência de processos de imigração e emigração nessas áreas (PEREIRA e DEMÉTRIO, 2014) em consonância ao quadro nacional (BAENINGER, 2011e 2012).

\begin{tabular}{lllll}
\hline Unidade Geográfica & $\mathbf{1 9 8 0}$ & $\mathbf{1 9 9 1}$ & $\mathbf{2 0 0 0}$ & $\mathbf{2 0 1 0}$ \\
\hline Brasil & 119.011 .052 & 146.825 .475 & 169.799 .170 & 190.755 .799 \\
São Paulo & 25.042 .074 & 31.588 .925 & 37.032 .403 & 41.262 .199 \\
RG de Ribeirão & 654.794 & 892.884 & 1.058 .652 & 1.246 .046 \\
Sertãozinho & 51.203 & 78.266 & 94.499 & 109.936 \\
RG de Araraquara & 326.700 & 443.409 & 512.664 & 569.405 \\
Matão & 37.822 & 63.154 & 71.669 & 76.743 \\
\hline
\end{tabular}

Tabela 2: População Residente no país, no Estado de São Paulo, nas RG de Ribeirão Preto e de Araraquara e nos municípios de Matão e Sertãozinho (1980-2010)

Fonte: Censos Demográficos de 1980, 1991, 2000 e 2010. Informações dos Municípios Paulistas (Fundação SEADE)

Baeninger (2000) destaca que, na década de 1990, verifica-se um fluxo bastante intenso de Nordestinos para o interior e para a Região Metropolitana de São Paulo. Assim, São Paulo vivenciou nas últimas décadas uma mudança significativa na distribuição de sua população. A autora também compreende que o chamado "interior" de São Paulo tendeu a ganhar população advinda de, pelos menos, dois fluxos migratórios: o primeiro que partia do sentido capital para interior e os que derivavam de outros estados brasileiros, como Paraná, Minas Gerais, Bahia, Pernambuco, Paraíba, Piauí (BAENINGER, 1999).

O Chamado "interior paulista", onde os migrantes começaram a chegar, já estava profundamente modificado, em alguns casos, pela desconcentração industrial (CANO, 1998) que se processou no Estado nas décadas de 1980 e 90. Baeninger (2000) ainda destaca que o interior de São Paulo passou a ser uma nova área de absorção de população nordestina. Vários trabalhos (SILVA, 1998; ALVES, 2007) indicam que o direcionamento de população do Nordeste para o Estado de São Paulo se intensificou com os avanços notados no mercado de trabalho rural, manual; o setor sucroalcooleiro e o de cítricos passaram a representar novas oportunidades para população migrante.

Segundo Silva (2007), tivemos a partir dos anos 2000, para a Região Central e de Ribeirão Preto, uma mudança significativa na cartografia migratória, com a presença cada vez mais assídua de populações do Piauí e Maranhão, outrora pouco significativos na composição das comunidades dessas Regiões. Formando um grande 


\section{SEMINÁRIO DE PESQUISA EM CIÊNCIAS HUMANAS - SEPECH \\ Humanidades, Estado e desafios didático-científicos \\ Londrina, 27 a 29 de julho de 2016}

contingente populacional de trabalhadores migrantes que podem ser considerados nos termos da autora como "permanentemente temporários" na região. Baeninger (2011, p.76) destaca que "os fluxos mais volumosos e de longa distância são compostos de idas-e-vindas, refluxos, re-emigração, outras etapas" diferentes daquelas vivenciadas em anos anteriores.

A maior parte dos trabalhadores que se assalariam temporariamente na safra de cana-de-açúcar e de cítricos do complexo agroindustrial paulista, para Silva (1992), vivem uma intensa circularidade que envolve o processo migratório permanente dos trabalhadores rurais e que não pressupõe a reprodução da mesma situação social:

Ao contrário. À volta, o caminho de fechar o círculo não é igual aos caminhos de iniciá-lo, por que a circularidade não ocorre uma única vez. Em muitos casos, ela acontece durante quase toda a vida destes agentes sociais. Nesse sentido, ela é permanente e o migrante temporário, é permanentemente temporário. Este é seu destino. Esta é sua história. Destino de um ser híbrido, isto é uma mistura de camponês e assalariado, mistura de duas condições sociais. Por isso, a reprodução da circularidade não reproduz a situação social de origem, mas a do ser híbrido [...] e produz a situação do ser e não ser ao mesmo tempo. (SILVA, 1992: 165).

Nesse processo de idas e vindas, conforme a autora, a ação dos sujeitos não ocorre de maneira aleatória e nem as condições puramente estruturais são capazes de explicar o fenômeno. Ainda de acordo com Silva (1992), há criação e invenção de vontade, desejos, aspirações, imaginação, fantasia e ilusões; o campo do simbólico e do imaginário "é um meio pelo qual os homens agem sobre eles mesmos: uma ação autoplástica" (Ibidem: 167). Para onde se retorna também é um questionamento apontado por Martins (1986), entendendo que o migrante:

Ao retornar, já não é o mesmo; e, por ter que sair, nas condições em que sai, modifica as relações sociais do seu grupo de origem, altera a organização familiar, e o lugar de cada um. O que encontra, quando retorna, já não é aquilo que deixou. Ele nem mesmo se reencontra porque já é outro, procurando ser o mesmo já não pode ver o mundo da mesma maneira que o via antes. (MARTINS, 1986: 45).

Para Sayad (2000), a respeito da transformação do sujeito que acontece no processo migratório:

A imigração não ocorre sem deixar marcas, frequentemente de maneira indelével, mesmo sem reconhecê-los, seja por nos atermos à ilusão da integridade formal e da fidelidade a si, seja por não sermos nem mesmo consciente disto. E, sem dúvida, o fato de não perceber que houve mudança no contato com os outros, dentre os quais vivemos, seria antes o sinal e a garantia da eficácia, da solidez e da perpetuação das mudanças sociais e culturais intervindas desta maneira, e testemunharia a sua irrevogável apropriação daquilo que interiorizamos profundamente e incorporamos totalmente no sentido literal da palavra (“eles se corporificam"). (SAYAD, 2000: 16). 


\section{SEMINÁRIO DE PESQUISA EM CIÊNCIAS HUMANAS - SEPECH \\ Humanidades, Estado e desafios didático-científicos \\ Londrina, 27 a 29 de julho de 2016}

Nessa conjuntura, ao pensarmos em sincronia à Martins (1986), Silva (1996) e Sayad $(2000,1998)$, temos como hipótese de trabalho que a condição de permanência temporária pode exercer fortes impactos nas subjetividades dos indivíduos que se deslocam, influenciando diretamente em suas escolhas e na produção de suas vidas.

\section{QUESTÕES EMERGENTES: O IMPACTO DAS MIGRAÇÕES TEMPORÁRIAS NAS TRAJETÓRIAS DE VIDA E LABORAIS NORDESTINOS PARA O INTERIOR DE SÃO PAULO.}

Silva e Medeiros (2010) registraram que durante a estada dos trabalhadores rurais migrantes maranhenses na cidade de Guariba no Estado de São Paulo para o corte de cana-de-açúcar as mulheres passavam de quebradeiras de coco babaçu nos cocais maranhenses para donas de casa na periferia desta cidade paulistas. Menezes e Silva (2010) no estudo realizado no sertão da Paraíba também entre famílias de trabalhadores rurais migrantes do corte da cana-de-açúcar em Sales, cidade do interior de São Paulo, ressaltava a importância da estada das mulheres enquanto "viúvas de maridos vivos" em seus locais de origem, propiciando a permanência dos roçados. Maciel e Pereira (2012) colocavam que a migração para as colheitas da laranja no interior de São Paulo, especialmente aquelas que partiam do Piauí para a cidade de Matão favoreciam mudanças significativas nas comunidades rurais da cidade de Jaicós quando as famílias deixam as casas fechadas e então partiam para a safra junto a seus esposos, deixando as comunidades rurais esvaziadas. Esses três estudos empíricos demostram o quão profunda são as modificações nas trajetórias de famílias de trabalhadores rurais migrantes entre o nordeste brasileiro e as colheitas do interior de São Paulo.

Para Bourdieu (1996b), a trajetória, discute é a objetivação no curso da vida das relações entre os agentes e as forças presentes no campo. Assim, a trajetória situa uma série de posições sucessivamente ocupadas pelos sujeitos no espaço social de lutas simbólicas. A trajetória é o movimento dentro do campo social de "possíveis" definidos estruturalmente, mesmo que as estratégias e os movimentos individuais pareçam ao acaso (BOURDIEU, 1996a).

Assim, a trajetória deve ser compreendida como uma maneira singular de percorrer o espaço social, onde se exprimem as disposições do habitus e se reconstitui uma série de posições sucessíveis que foram ocupadas por um mesmo agente ou por um grupo em espaços sucessíveis (BOURDIEU, 1996a). Os adquiridos os capitais e conforme sua distribuição, os agentes se movem dentro de um determinado campo, operando colocações e deslocamentos. Deste modo ao considerar as trajetórias dos trabalhadores rurais migrantes permanentemente temporários no interior de São Paulo, verificamos a partir de estudos empíricos, algumas de questões que gostaríamos de ressaltar nesse artigo que se referem à complexidade da trajetória social:

1) Fraturas na ordem das espacialidades e temporalidades

- O Reordenamento das comunidades de origem na região Nordeste brasileira

- As mudanças significativas das cidades de destino ocasionadas pela chegada dos migrantes.

Através das pesquisas de campos selecionadas foi possível perceber que as idas e vindas desses trabalhadores rurais migrantes passavam a reorganizar a vida dos lugares 


\section{SEMINÁRIO DE PESQUISA EM CIÊNCIAS HUMANAS - SEPECH \\ Humanidades, Estado e desafios didático-científicos \\ Londrina, 27 a 29 de julho de 2016}

de origem e destino. No caso, do estudo realizado nas cidades de Matão (SP) ${ }^{5}$ e Jaicós $(\mathrm{PI})^{6}$ verificamos que ambos se modificavam na presença e ausência dos migrantes. $\mathrm{Na}$ primeira, a intensificação do volume de trabalhadores rurais migrantes durantes os meses de junho a dezembro aquecia o comercio local e o mercado imobiliário informal. $\mathrm{Na}$ segunda, as comunidades rurais e os bairros vivenciavam a ausência de seus moradores habituais, assim, as casas permaneciam fechadas no período da safra da laranja no interior paulista.

Em Jaicós entre os anos de 2012 e 2014, eram diversas atividades antes ocupadas pelos trabalhadores rurais que deixavam de ser realizadas como os projetos pelo Sindicato dos Trabalhadores rurais para a convivência no semiárido. Menezes e Silva (2010) verificam que na Paraíba, como as mulheres eram as que ficavam havia a preservação dos roçados, e a espera dos maridos para a colheita da produção do que foi plantado antes da migração sazonal. Com a volta dos migrantes as comunidades tomam outro ritmo, e a circulação de motos e carros, adquiridos na safra são constantes, há também a realização de festas e o aquecimento da economia local, com a compra de produtos, sobretudo para a casa familiar.

Desse modo, os trabalhadores tanto da colheita da laranja, quanto do corte de cana-de-açúcar vivenciam suas trajetórias sociais divididas em dois tempos: $\mathrm{O}$ da safra no interior de São Paulo e a da entressafra em suas comunidades de origem. Em algumas comunidades rurais do nordeste como verificado em Jaicós (PI), o tempo da entressafra é o tempo para descansar, para a próxima safra e visitar os amigos e familiares, a produção na pequena propriedade vem perdendo força nos últimos anos. Nesse sentido, visualizamos a constituição de dois espaços rurais como modos de vida (WANDERLEY, 2009, MACIEL, 2016): o local de resguardo e descanso nas comunidades rurais do interior piauiense, e o local do trabalho nos pomares de laranja no interior paulista.

\section{2) Fraturas na organização familiar}

- A inserção da mão-de-obra feminina nos laranjais e canaviais e o impacto sobre a subjetividade das mulheres migrantes.

- Os filhos da mobilidade: crianças nascidas e crescidas no lá e cá.

As mulheres possuem um papel importante e estratégico nos processos migratórios estudados. Quando elas ficam, como mostrado por Menezes e Silva (2010), são responsáveis pelo plantio e cuidado do roçado, mas também são importantes para a manutenção da rede de afetos e familiar no migrante na comunidade de origem, são elas que mantêm o vínculo do marido mesmo com a terra. Assim, as mulheres são geradoras de uma econômica local, porém a ausência do esposo também faz com que sejam reorganizadoras das atividades familiares e gestão dos gastos, bem como do dinheiro enviado pelo marido.

Porém, quando as mulheres partem com seus maridos - lembrando que a migração permanentemente temporária para as safras, em vários estudos se apresenta as mulheres via algum homem seja o pai ou esposo - passam atuar no mercado de trabalho da safra, o rural, mas também o urbano, quando se empregam nas ditas "casas de

\footnotetext{
${ }^{5}$ Matão possui uma população de cerca de 80 mil habitantes segundo dados do Censo Demográfico 2010. Maiores informações sobre a cidade ver PEREIRA (2015).

${ }^{6}$ Jaicós possui uma população de 18 mil habitantes, também segundo dados do Censo Demográfico 2010.
} 


\section{SEMINÁRIO DE PESQUISA EM CIÊNCIAS HUMANAS - SEPECH \\ Humanidades, Estado e desafios didático-científicos \\ Londrina, 27 a 29 de julho de 2016}

família" nas cidades onde passam a morar, e assim, assumem uma dupla jornada de trabalho, considerando que a manutenção da casa familiar e apoio ao marido são de grande importância para a produtividade do trabalhador seja do corte de cana-de-açúcar ou colheita da laranja.

No corte-de-cana de açúcar a força de trabalho feminino quando não excluída foi alijada a trabalhos considerados "mais leves", segundo estudos de Silva (1998; 2010; 2014) as mulheres são alocadas na faxina do canavial, processo acelerado com a introdução das máquinas. Na colheita da laranja o trabalho das mesmas é posicionado de diferente modo, as mulheres são empregadas na colheita com os homens, e seus níveis de produtividade não diferem muito dos mesmos. Porém, ambas as atividades inseriram as mulheres no mercado de trabalho formal o que possibilitou que elas pudessem gerir seus rendimentos de maneira mais autônoma, fora do mando patriarcal. Tal condição, como verificado em trabalho de campo, passou alterar as relações que possuem com suas famílias, principalmente frente a pai ou marido.

As mulheres também se apresentam como as principais agentes da rede de cuidados configurada entre o "lá" e o "cá". Desse modo, em episódios de doença ou falecimento de entes próximos, as mesmas retornam para o Piauí, pois são acionadas por suas redes de parentesco e afinidade para o auxílio dos demais parentes ou amigos.

Nessas idas e vindas são muitas as crianças que nascem e são criadas seguindo os pais entre os espaços da migração. As mulheres ao passo que engravidam durante a safra, geralmente segue para a casa familiar em suas comunidades de origem, pois impossibilitadas ao trabalho árduo da safra, passam a representam um ônus para seu esposo nos locais de destino, assim, pela gestão familiar, é melhor que fiquem na casa familiar no nordeste. Em mesma medida, a gravidez apresenta-se como importante transição para a vida dessas mulheres, nesse sentido, retornar aos "cuidados da mãe" implica, inclusive, em aprender e reorganizar seu novo papel social.

Em Jaicós (PI) tal aspecto foi apresentado pela figura do "matonensinho", crianças de pais jaicoenses nascidas em Matão e chamadas pela população local por esse apelido. Essas crianças desde o nascimento já trazem as marcas dos espaços por onde seus pais circularam. Possuem suas vidas dividas também em dois tempos em espaços sociais, o que influencia diretamente na escolaridade feita pelas metades entre uma cidade e outra.

3) Fraturas na organização e exploração da força de trabalho dos migrantes permanentemente temporários

- Entre o rural do agronegócio paulista e o roçado no nordeste: A árdua aprendizagem;

- Produtividade: Pai e mãe da turma versus o Aranha - na colheita da laranja.

Aprender a circular nos espaços de sociabilidade do trabalho formal, ofertado nas colheitas agrícolas do interior de São Paulo, é certamente um dos desafios a ser vencidos pelos migrantes permanentemente temporários. Os trabalhadores do setor agrícola do interior de São Paulo, os safristas, são na maior parte das vezes trabalhadores que possuem algum vinculo com a terra. No entanto, a organização da produção nas safras se assemelha as da indústria, (Alves 2010; Verçosa, 2012) mostra as praticas "fordistas" empregadas nessa cadeia produtiva, o que exige dos trabalhadores, antes pequenos proprietários e rendeiros, a aprendizagem de outra lógica de trabalho. A primeira dela a gestão do tempo de trabalho cronometrado e a segunda a gestão da produtividade. 


\section{SEMINÁRIO DE PESQUISA EM CIÊNCIAS HUMANAS - SEPECH \\ Humanidades, Estado e desafios didático-científicos \\ Londrina, 27 a 29 de julho de 2016}

A produtividade entre os trabalhadores rurais da cana-de-açúcar é uma questão bastante discutida na literatura especializada (Alves e Novais, 2010; Silva, 2010; 2014; Guanais, 2010,), tal questão foi central para importantes greves, como a de Guariba em 1985 (Vetoriassi, 2007), amplamente rememorada pelos trabalhadores rurais. A luta por melhores condições de trabalho nas lavouras paulistas e nos alojamentos também se apresentam como problemáticas importantes para os trabalhadores rurais migrantes.

A condição temporária desses trabalhadores os coloca em uma dura encruzilhada: ao mesmo tempo em que reivindicam melhores condições de trabalho sofrendo duras sanções do empregador pelo envolvimento com os movimentos sindicais e a recusa das árduas condições de trabalho, eles também se submetem as duras jornadas atingindo altos níveis de produtividade, pois a condição de temporalidade os coloca frente a eminente partida e a necessidade da reprodução ou produção de novas condições sociais em seus locais de origem.

No caso dos trabalhadores da laranja, em 2012, na cidade de São Carlos, a produtividade de um trabalhador rural migrantes de permanência mais estável nessa cidades e geralmente morador da preferia urbana, era de 100 caixas por dia (Maciel, 2013); já entre os trabalhadores rurais permanentemente temporários migrantes de Jaicós (PI) em Matão, a média era de 170. Nesse cenário, as formas de controle da produtividade apresentavam-se de maneira formal, pela presença do fiscal de turma em meio as ruas dos laranjais, e também de maneira tão eficaz quanto a outra, aparecia através das micros relações gestadas pelos trabalhadores, é nesse contexto que categorias como "pai" e "mãe" da turma e "aranha" surgem.

Pai e mãe da turma são os melhores colhedores de um grupo de trabalhadores rurais, os "aranhas" são categorizadas com aqueles trabalhadores "fracos" de produção. Essas categorias são utilizadas para classificar e estigmatizar os trabalhadores. Para lembralhe que é necessário ser produtivo, pois, o único sentido de estar na safra, ou de estar na roda viva da migração permanentemente temporária é conseguir auferir maiores ganhos para reproduzir as condições sociais de vida (Menezes, 2002) ou mesmo para produzir novas espacialidades e identidades sociais mesmo que fraturadas (Maciel, 2016).

As experiências migratórias que incluem os diversos deslocamentos entre o nordeste e o interior de São Paulo alteram definitivamente as biografias laborais e familiares dos trabalhadores e trabalhadoras do moderno complexo agro produtivo paulista que vivenciam suas vidas em dois tempos e espaços sociais de vida, a eles são destinados pouca visibilidade, mas são sua mão-de-obra é, certamente, o motor da grandeza do complexo produtivo.

\section{À GUISA DE UMA CONCLUSÃO}

$\mathrm{O}$ artigo buscou compreender as subjetividades presentes nos processos migratórios vinculados ao trabalho rural do agronegócio citrícola do Estado de São Paulo. Ao compreendermos que os espaços migratórios e consequentemente a mobilidade populacional se constituem a partir de contextos sócios históricos delineados pela atuação do capital no território brasileiro (BALÁN, 1974; CANO, 2011; BAENINGER, 2012), almejamos o entendimento dos atores sociais e suas subjetividades, compondo, assim, uma análise que articule os níveis macro e microssociais. A análise das trajetórias possibilitou ao acessar múltiplas dimensões da 


\section{SEMINÁRIO DE PESQUISA EM CIÊNCIAS HUMANAS - SEPECH \\ Humanidades, Estado e desafios didático-científicos \\ Londrina, 27 a 29 de julho de 2016}

vida social dos migrantes em seus locais de origem e destino a visibilidade de um complexo mosaico de interações sociais aqui descritas ainda de maneira resumida.

\section{REFERENCIAS BIBLIOGRÁFICAS}

ALVES, F. Migração de trabalhadores rurais do Maranhã e Piauí para o corte de cana de São Paulo. Será esse um fenômeno casual ou recorrente da estratégia empresarial do complexo agroindustrial canavieiro? In: NOVAES, J. R. P; ALVES, F. J. C (Orgs.). Migrantes: trabalho e trabalhadores no complexo agroindustrial canavieiro (os heróis do agronegócio brasileiro). São Carlos: EdUFSCAR, 2007.

BAENINGER, R. Região Administrativa Central: Região de Governo de Araraquara e Região de Governo de São Carlos. Textos NEPO 31: Migração em São Paulo 7. Núcleo de Estudos de População/Unicamp. Campinas. 1995.

, R A. Região, Metrópole e Interior: espaços ganhadores e espaços perdedores nas migrações recentes- Brasil, 1980-1996. Campinas. Tese (Doutorado) Instituto de Filosofia e Ciências Humanas, Universidade Estadual de Campinas. 1999.

- Migrações internas no Brasil no século 21: evidencias empíricas e desafios conceituais. Mobilidade espacial da população. Desafios teóricos e metodológicos para seu estudo. CUNHA, J. M. (org.) - Campinas: NEPO/Unicamp. 2011.

, R. Fases e Faces da migração em São Paulo. Núcleo de Estudos de População-Nepo/Unicamp. Campinas. 2012.

BALÁN, J. Migrações e Desenvolvimento Capitalista no Brasil: Ensaio de Interpretação Histórico-Compartativa. Centro e Periferia no Desenvolvimento Brasileiro. São Paulo: Difusão Européia do Livro. 1974.

BOURDIEU, P. Razões Práticas. Sobre a teoria da ação. Campinas, SP. Papirus.1994.

As regras da arte: gênese e estrutura do campo literário. São Paulo: Cia das Letras. 1996 a.

. EAGLETON, T. A doxa e a vida cotidiana: uma entrevista. In: ZIZEK, Slavoj (Org.). Um mapa da ideologia. Rio de Janeiro: Contraponto, $1996 \mathrm{~b}$.

CANO, W. Novas determinações sobre as questões regional e urbana após 1980. Texto para Discussão $\mathbf{N}^{\mathbf{0}}$ 193. Julho/2011. Instituto de Economia-Unicamp. Campinas.

CORRÊA, Roberto Lobato. Estudos sobre a rede urbana. Rio de Janeiro. Editora Bertrand Brasil. 2006.

ELIAS, D. Globalização e Agricultura. São Paulo. EdUSP. 2003. , D e PEQUENO, R. (orgs). Difusão do Agronegócio e Novas Dinâmicas Socioespaciais. Banco do Nordeste. Fortaleza. 2006. 


\section{SEMINÁRIO DE PESQUISA EM CIÊNCIAS HUMANAS - SEPECH \\ Humanidades, Estado e desafios didático-científicos \\ Londrina, 27 a 29 de julho de 2016}

D. e PEQUENO, R.. Desigualdades Socioespaciais nas Cidades do Agronegócio. Anais do XII Encontro da Associação Nacional de Pós-Graduação e Pesquisa em Planejamento Urbano e Regional. Belém, 2007.

D. Agronegócio e Novas Regionalizações no Brasil. Revista Estudos Urbanos e Regionais, v. 13, n. 2. Novembro/2011.

D. Regiões Produtivas do agronegócio: Notas teóricas e metodológicas. In Espaço e Energia: Mudanças no paradigma sucroenergético. BERNARDES, J.A.; SILVA, C.A.; ARRUZZO, R.C. (orgs). Editora Lamparina. Rio de Janeiro. 2013.

GUANAIS, J. No eito da cana, a quadra é fechada: estratégias de dominação e resistência entre patrões e cortador de cana em Cosmópolis/SP. Dissertação de mestrado. IFCH. Unicamp. Campinas, 2010.

MARTINS, J. S. Não há terra para plantar neste verão. Petrópolis, 1986.

MACIEL, L. Entre o rural e o urbano: processos migratórios de trabalhadores rurais do Alto e Médio Canindé piauiense para a Região Central do Estado de São Paulo. Tese de doutorado. Programa de Pós-graduação em Sociologia. Unicamp. 2016.

.PEREIRA, G. G. . Do interior para os laranjais, dos laranjais para o interior: a migração de piauienses para a Região Central de São Paulo. In: VIII Encontro Nacional Sobre Migrações, GT Migração ABEP, 2013, Belo Horizonte. Anais do VIII Encontro Nacional Sobre Migrações, GT Migração ABEP, 2013.

MENEZES, M.Redes e enredos nas trilhas dos migrantes: um estudo de famílias de camponeses-migrantes. ED: Relume Dumará. Paraíba; 2002.

MÜLLER, Geraldo. A Dinâmica da Agricultura Paulista. Série São Paulo 80 v.2. São Paulo. Fundação SEADE. 1985

PACHECO, Carlos Américo. Café e cidades em São Paulo: Um estudo de caso da urbanização da região de Araraquara e São Carlos 1880/1930. Dissertação de Mestrado. Instituto de Economia/Unicamp. Campinas. 1988.

PEREIRA, G G. e DEMÉTRIO, N.B. Migrações, Agronegócio e Populações Rurais: Convivência, Interdependência e Pluralidade de Atores e Processos nas Cidades do Agronegócio paulistas. In Anais do XIX Encontro Nacional de Estudos Populacionais. ABEP. Águas de São Pedro. 2014.

G. G. Entre o partir e o chegar: Os trabalhadores rurais migrantes em Matão/SP. Dissertação de Mestrado. Instituto de Filosofia e Ciências Humanas. Unicamp. 2015

PIRES, M. C. S. Região de Governo de Ribeirão Preto. Textos Nepo 30 - Migração em São Paulo. Nepo/Unicamp. 1995. 
RENNER, C.H., PATARRA, N.L. Migrações. In: SANTOS, 1.L.F. et. aI (Coord). Dinâmica da população: teoria, métodos e técnicas de análise. São Paulo: T.A. Queiroz, 1980. p.236-260.

SAYAD, A. (1998). A Imigração; os Paradoxos da Alteridade. São Paulo: Editora da USP. 1988.

- O retorno: elemento constitutivo da condição do imigrante. In: Travessia, ano XIII, n. esp., janeiro de 2000.

SILVA, M. A. de M. Destino e trajetória de camponeses migrantes. In: Anais do VIII Encontro Nacional de Estudos Populacionais, Vol. 3. 1992.

.Errantes do fim do século. São Paulo: Editora da UNESP, 1998.

SILVA, M. L. A inserção internacional das grandes empresas nacionais. Internacionalização e Desenvolvimento da Indústria no Brasil. Laplane, $M$; Coutinho, L. e Hiratuka, C. (orgs). Coleção Economia Contemporânea. Editora UNESP. São Paulo. 2003.

VETTORASSI, A. Migrantes do Interior Paulista: sobre relações sociais traçadas por violências simbólicas. Teoria \& Pesquisa, v. 49, p. 213-237, 2007.

VERÇOZA, L. V. Trabalhadores nos canaviais de alagoas: Um estudo sobre as condições de trabalho e resistência. Dissertação de mestrado PPGS. São Carlos. 2012

WANDERLEY, M. N. B. O mundo rural como um espaço de vida: reflexões sobre a propriedade da terra, agricultura familiar e ruralidade. Porto Alegre: Editora da UFRGS, 2009. 